\title{
THE DISTRIBUTION OF MUSCINA PASCUORUM MEIGEN IN AMERICA.
}

\author{
By Charles W. Johnson, \\ Boston Society of Natural History.
}

The last report on the distribution of this fly in North America was for 1923 (Psyche, vol. 31, p. 17, Feb. 1924).

During 1924 the fly was apparently quite scarce in the vicinity of Boston and no additional records bearing on its distribution were received. Mr. R. C. Shannon however reported one specimen (o ) from Plummers Island, Md., Nov. 11, 1923 (Ent. News, vol. 35, p. 104, March 1924) and common in cupolas (all females) at South Poland, Maine, May 1924 (Proc. Ent. Soc. Wash., vol. 26, p. 146, May 1924).

During the fall of 1925 after the rains in September it again appeared in eastern Massachusetts and I began to receive reports of its entering houses in considerable numbers. During the first week in October a few appeared each day on the windows at the museum and at my home in Brookline. Mr. N. P. Woodward sent me specimens from Worcester, Mr. D. S. Lacroix reported it common at the State Cranberry Station, East Wareham. Mrs. Hathaway sent me specimens on October 10 from East Bridgewater. Dr. Francis Harper collected a number at Natick, October 16. Mr. W. L. Maxcy sent me a number from Still River, October 20 and Mr. F. W. Walker found it common in a cottage at Middleton, Nov. 15. My friend, the late Lewis B. Woodruff wrote me Oct. 19 that it was plentiful on his windows at Litchfield, Conn. Mr. N. K. Bigelow informs me that it is now common in parts of Ontario and sent me specimens collected at Port Hope, Sept. 5, 1925.

Dr. A. H. Sturtevant in a letter dated October 17, 1925 says"I have just noticed that your friend Muscina pascuorum is now common on the windows here. I have never seen it in New York [City] before, but cannot guarantee that it has not been fairly common before since I do not check up carefully on Calypteræ." 
Later he writes- "I found Muscina pascuorum in an attic at Morristown, N. J., Oct.19, 1925, I have seen no males, but two females from New York and one from Morristown, that I dissected, all had active sperm in their receptacles. Evidently the females mate before they come indoors to hibernate."

The distribution of this species is probably much greater than has been recorded. It is readily overlooked as many of the species of Muscidæ are similar in appearance and have the same habit of entering houses as the weather becomes cool in the fall. Its life history in America is still unknown. 

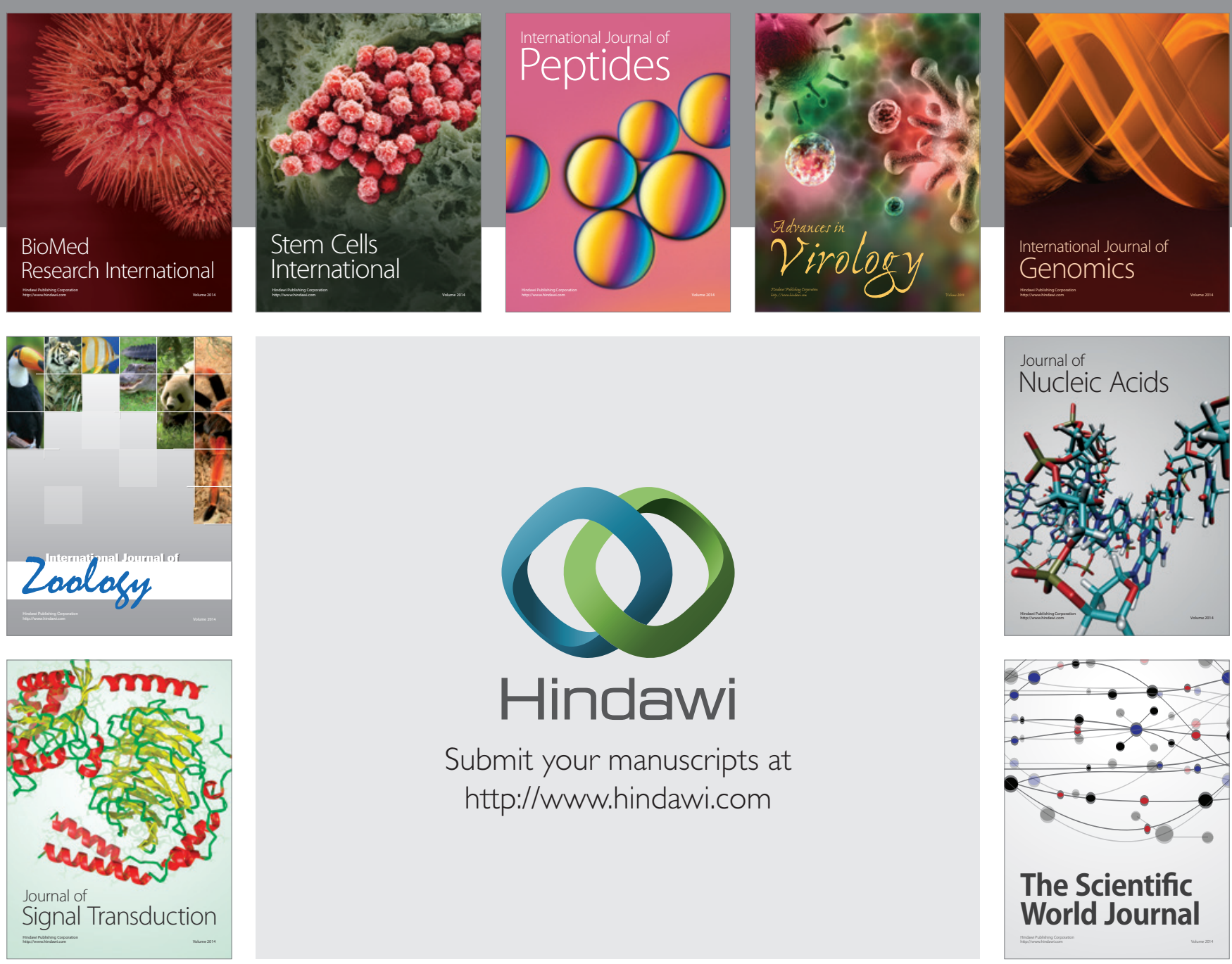

Submit your manuscripts at

http://www.hindawi.com
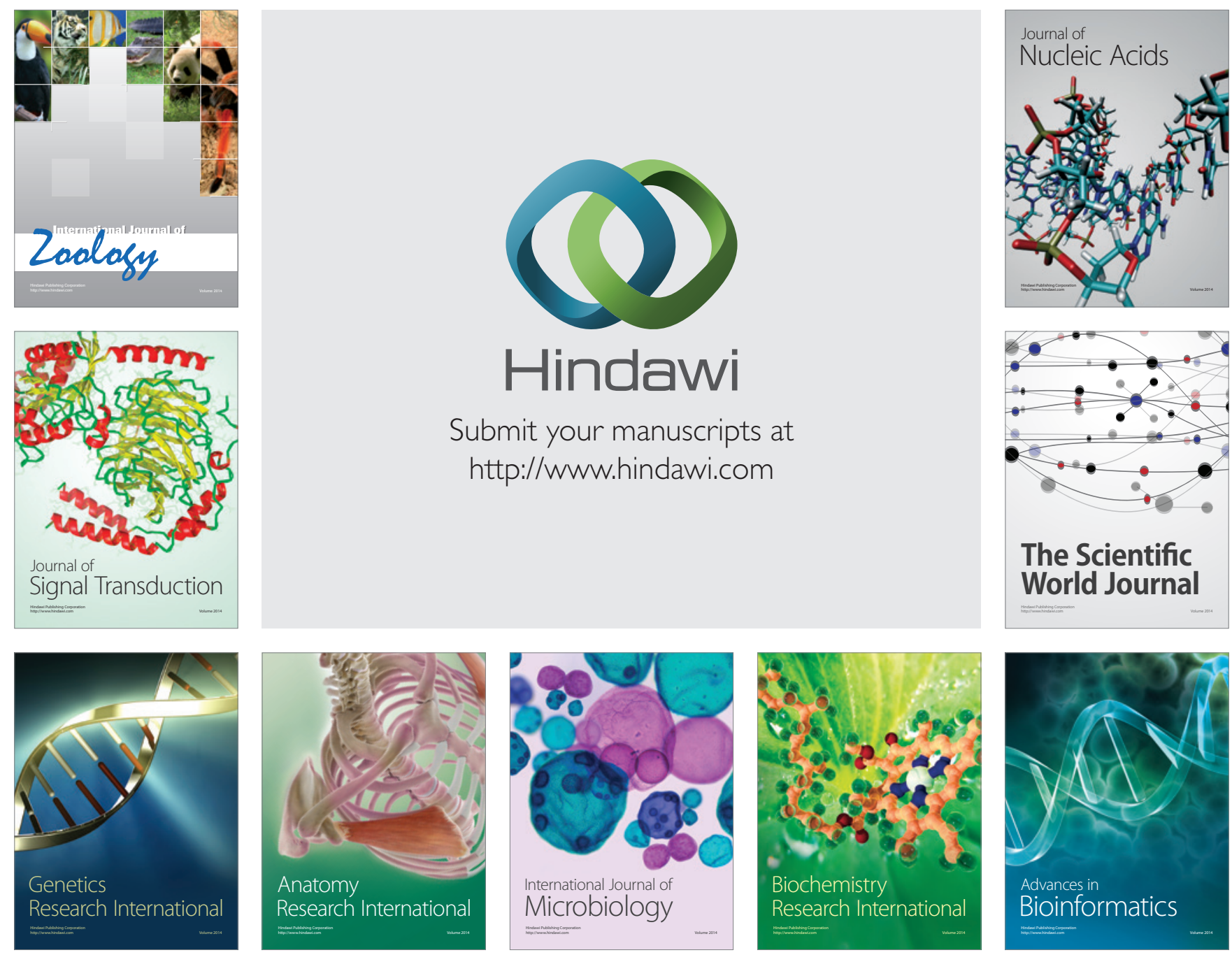

The Scientific World Journal
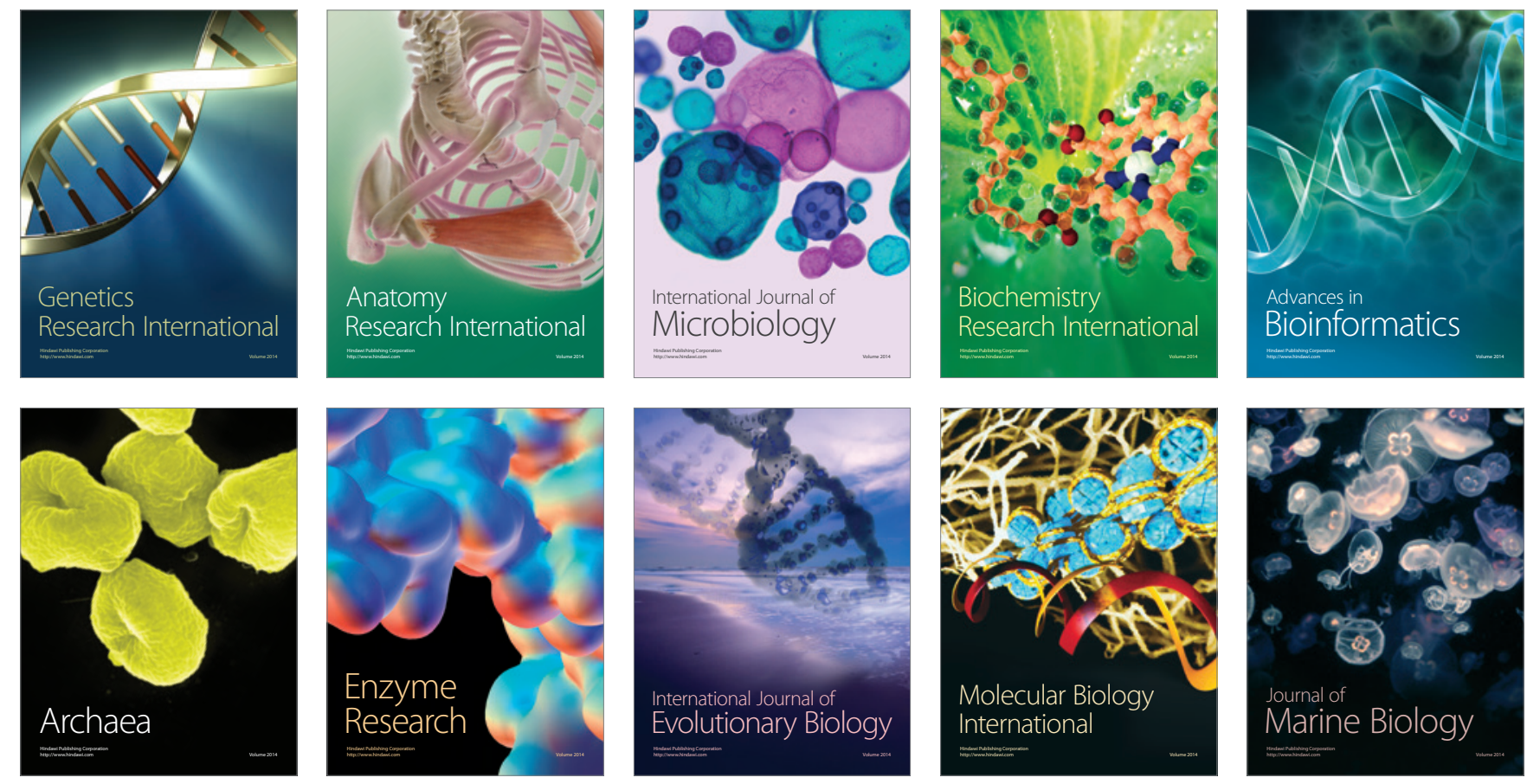